\title{
Assessment of a revolving drug fund for essential asthma medicines in Benin
}

\author{
Gildas Agodokpessi', Nadia Ait-Khaled², Martin Gninafon', Leon Tawo', Wilfried Bekou', Christophe Perrin², \\ Karen Bissell ${ }^{2}$, Nils Billo², Donald A Enarson ${ }^{2}$ and Chen-Yuan Chiang ${ }^{2,3,4^{*}}$
}

\begin{abstract}
Objectives: Benin established a revolving drug fund (RDF) for essential asthma medicines in 2008. We evaluated the operation of the RDF and assessed whether there was interruption of supply of asthma medicine from 2008 to 2013.

Methods: We reviewed the process in establishing the RDF. We assessed cost and sale price of asthma medicines, expenditure of the RDF in procuring asthma medicines and other tools, revenue generated by sales of medicines to patients, and balance of capital as of 31 January 2013. We investigated whether there was interruption of supply of essential asthma medicines from 2008-2013.

Results: The total amount of grants initially injected into the RDF was 24,101€. As of 31 January 2013, the capital of the RDF, including the deposit in the RDF bank account $(8,114 €)$ and the value of inhalers in stock $(12,172 €)$, was equivalent to $20,586 €$, slightly less than the initial capital $(24,101 €)$. The decrease of capital was mainly because a number of inhalers were expired or provided free-of-charge $(6,091 €)$ and because part of the fund was used to procure other elements required for the management of asthma (4,338€). Thanks to a RDF, Benin maintained an uninterrupted supply of essential asthma medicines in asthma pilot sites from 2008-2013.
\end{abstract}

Conclusion: The Benin experience demonstrated that in countries where universal health coverage was not yet in place, establishment of a RDF may help maintain an uninterrupted supply of essential medicines.

Keywords: Asthma, Revolving drug fund, Beclometasone, Inhaled corticosteroid

\section{Introduction}

Shortage of pharmaceutical supply is common in resource-limited settings. Access to affordable essential medicines for non-communicable diseases in resource limited settings can be particularly challenging [1,2]. The low affordability of essential asthma medicines, in particular the inhaled corticosteroid (ICS), was identified as one of the main barriers in providing proper asthma care in low- and middle-income countries [2-7]. Revolving drug funds have been applied in a variety of settings to address this problem through financing drug supply [8-11]. It usually begins with an initial capital investment,

\footnotetext{
* Correspondence: cychiang@theunion.org

${ }^{2}$ International Union Against Tuberculosis and Lung Disease, 68, boulevard Saint-Michel, 75006 Paris, France

${ }^{3}$ Division of Pulmonary Medicine, Department of Internal Medicine, Wan Fang Hospital, Taipei Medical University, Taipei, Taiwan

Full list of author information is available at the end of the article
}

followed by replenishment of drug stock with monies collected from the sale of medicines.

A project introducing a comprehensive approach to lung health (CAL), funded by the World Bank and implemented through collaboration between the International Union Against Tuberculosis and Lung Disease (The Union) and partners in Benin, China and Sudan, included as one of its aims to reduce the burden of lung disease through management of patients with persistent asthma $[12,13]$. In Benin, it was implemented in 2008 at two public health facilities (Centre national hospitalier de pneumophtisiologie (CNHP) in Cotonou and one tuberculosis unit located in Porto-Novo) and three missionary health facilities. For the implementation of standard case management of asthma, it was decided to establish a revolving drug fund (RDF) for essential asthma medicines to ensure uninterrupted supply of essential asthma medicine. In this 
paper, we evaluated the operation of a RDF for asthma from 2008 to 2013.

\section{Methods Setting}

Benin is a low income country where universal health coverage is not yet in place. Most asthma patients have had to pay out of pocket for health services. Before the asthma pilot project, the majority of asthma patients were being treated exclusively on an emergency basis when they presented with an acute attack of asthma and that only a small minority of asthma patients were prescribed with ICS in Benin [12].

\section{Establishment of a revolving drug fund for essential asthma medicine}

Before the CAL project implementation, the Benin national tuberculosis programme (NTP) manager and The Union consultant discussed whether asthma inhalers should be provided free-of-charge to asthma patients or whether it would be more sustainable to establish a RDF for essential asthma medicines. As asthma is a chronic disease and long term management is required, maintaining uninterrupted supply of affordable asthma medicines is essential for ensuring the continuity of care. There was concern that if asthma inhalers were provided at no cost to patients, the supply of asthma inhalers might be interrupted when the project finished. Thus, part of the World Bank grant was used as an initial capital investment to establish a RDF for asthma medicines that would aim to sustain long term management of asthma in five asthma pilot sites.

The coordinator of the asthma projects and the RDF was the NTP manager, who was also the director of the biggest site for asthma management (the CNHP). A dedicated bank account for the RFD was created; monies collected from the sale of asthma inhalers were deposited in the RFD bank account for further procurement of asthma inhalers.

\section{Initial capital of RDF}

The initial capital invested into the CAL project in 2008 for procuring asthma medicines was $9,940 €$. With this, Benin's NTP manager purchased 2,000 units each of inhaled beclometasone (200 puffs, $250 \mu \mathrm{g}$ per puff) and of inhaled salbutamol through Benin's central pharmacy for essential medicines (CAME). Due to a delay in delivery of medicines at the beginning of project implementation, the CAME donated 320 inhalers of beclometasone (total $1,203 €)$, which allowed the project to commence and added to the value of the RDF. Until the ordered medicines arrived, patients had to buy inhaled salbutamol at a private pharmacy. The total grant provided to the CNHP to establish the RDF for asthma for the CAL project, including the medicines donated by the CAME, was $11,143 €$.

\section{Asthma drug facility and additional capital of RDF}

The Union created the Asthma Drug Facility (ADF), which aimed to provide affordable access to qualityassured essential asthma medicines for low- and middleincome countries [14,15]. The ADF pooled requests from qualifying programmes for quality-assured essential asthma medicines. It used bi-yearly international competitive bids to offer the most affordable prices possible for asthma medicines after a qualification procedure ensuring the selection of inhalers in strict compliance with international quality standards. To pilot the operations of the ADF, The Union and the Benin NTP agreed that The Union would donate inhaled medicines and provide training and technical assistance for the implementation of standard case management of asthma, and that the Benin NTP would maintain the RDF for asthma to procure essential asthma medicines through the ADF for the following three years. It was agreed that a small margin should be added to the cost of the medicines procured through the ADF to cover customs clearance, storage, distribution, and potential loss of drugs, and to slightly increase the amount of the fund to ensure sustainability. The Union donated 2,500 units of inhaled beclometasone propelled by hydrofluoroalkanes (HFA) $(100 \mu \mathrm{g}$ per puff, 200 puffs) and 2000 HFA inhaled salbutamol (100 $\mu \mathrm{g}$ per puff, 200 puffs), equivalent to $7530 €$, to Benin through the ADF in 2010 for the implementation of the ADF pilot project.

In addition to medicines, both the CAL project and the ADF pilot project funded other project elements, such as training, coordination, supervision, purchase of peak flow meter, spirometers, and mouthpieces, and the printing of asthma treatment cards and treatment registers as well as posters for patient education. At the end of the projects, $5,428 €$ remained unspent and were injected into the RDF.

\section{Maintaining the RDF}

The CNHP was responsible for the distribution of inhalers to other pilot sites and maintaining the RDF. The sites charged patients at the selling price recommended by CNHP without adding a site margin during the first project year. All these sites agreed to conduct quarterly follow-up and to manage asthma attacks free-of-charge (the usual consultation fee was about $0.30 €$ ). After the end of the one year ADF pilot project, the three missionary sites decided unilaterally to add a site margin for the management of asthma drugs and increased the cost of both inhaled beclometasone and inhaled salbutamol by $0.3 €$ per inhaler, which did not return to the RDF. In March 2011, the Benin NTP Director, after discussion 
with The Union consultants, decided to impose a markup of $0.30 €$ per inhaler as a site margin in order to standardise the selling price of inhalers and to maintain the services of follow-up at no cost to patients at all sites.

\section{Medicine management tool}

A medicine management tool using Microsoft Excel has been developed for the management of asthma inhalers. It was used periodically to assess number of inhalers in stock at the beginning of a period; number of inhalers ordered during that period; number of inhalers in stock at the end of the period; number of inhalers used during the period; average monthly consumption of inhalers; number of months that inhalers in stock can cover. This information was then used to estimate the date for placing the next order of inhalers, aiming to order 8 months before the inhalers would run out (a two-month buffer plus six months as the estimated interval between placing an order to receiving the medicines).

\section{Evaluation of the RDF}

To evaluate the RDF in Benin, we reviewed the costs of procuring the asthma medicines, the price at which medicines were sold to patients, costs for procuring other elements related to the management of asthma (peak flow meters, mouthpieces, printing of asthma treatment cards and registers), the revenue generated by selling medicines to patients, and the balance of capital as of 31 January 2013. We assessed the performance of the medicine management tool and check whether there was interriuption of essential asthma medicine at projct sites.

The asthma projects focused on long-term management of patients with persistent asthma. The second edition [16] of The Union's guide for standard case management of asthma was used in the CAL project; the third edition
[17] was used in the ADF project. We reviewed registration of asthma patients for standard case management of asthma during the period 2008-2011.

\section{Ethics}

As the information collected was a part of routine health service operations in Benin, review by an ethics committee was not considered to be required. All information was handled by the health care workers who provided care for the patients on a routine basis. No individual identifiers were provided to individuals outside the health service.

\section{Results}

Table 1 shows that the total amount of grants injected into the RDF over the period of 2008-2010 was $24,101 €$.

\section{Medicines prices for the CAL and ADF projects}

Table 2 shows that in the CAL project the purchase price of inhaled salbutamol, propelled by chlorofluorocarbons (CFC), was $0.95 €$ and that of CFC inhaled beclometasone $3.50 €$. With a $14 \%$ margin set by the NTP, the selling price was $1.37 €$ for inhaled salbutamol and $4.27 €$ for inhaled beclometasone.

The cost of ADF inhaled beclometasone was $1.78 €$, about half of the cost of inhaled beclometasone procured locally during the CAL project. The cost of ADF inhaled salbutamol was $1.54 €$, about $27 \%$ higher than that of inhaled salbutamol procured locally during the CAL project (Table 2). With an average of $10 \%$ margin, the selling price was $1.98 €$ for inhaled beclometasone and $1.68 €$ for inhaled salbutamol in the ADF pilot project.

\section{Table 1 Grants that contributed to Benin's revolving drug fund, 2008-2013}

\begin{tabular}{|c|c|c|c|}
\hline & Number of inhalers & Price per inhaler $(€)$ & Amount of money $(€)$ \\
\hline 1. CAL Project & & & 11143 \\
\hline \multicolumn{4}{|l|}{ Grant from World Bank } \\
\hline Inhaled beclometasone & 2,000 & 3.76 & 7,520 \\
\hline Inhaled salbutamol & 2,000 & 1.21 & 2,420 \\
\hline \multicolumn{4}{|l|}{ Donation from CAME } \\
\hline Inhaled beclometasone & 320 & 3.76 & 1,203 \\
\hline 2. Donation from Asthma Drug Facility project & & & 7,530 \\
\hline Inhaled beclometasone & 2,500 & 1.78 & 4,450 \\
\hline Inhaled salbutamol & 2,000 & 1.54 & 3,080 \\
\hline 3. Grant in medicines $(1+2)$ & & & 18,673 \\
\hline 4. Grant in cash & & & 5,428 \\
\hline 5. Total revolving fund grant $(3+4)$ & & & 24,101 \\
\hline
\end{tabular}

Note: CAL, comprehensive approach to lung health project; CAME, central pharmacy for essential medicines of Benin. 
Table 2 Purchase price, freight fee, margin and selling price for inhaled beclometasone and inhaled salbutamol in a comprehensive approach to lung health project and an asthma drug facility pilot project in Benin

\begin{tabular}{lll}
\hline & $\begin{array}{l}\text { Inhaled } \\
\text { Beclometasone }(\boldsymbol{\epsilon})\end{array}$ & $\begin{array}{l}\text { Inhaled } \\
\text { Salbutamol }(\boldsymbol{\epsilon})\end{array}$ \\
\hline CAL Project & & \\
a) Purchase price & 3.50 & 0.95 \\
b) Freight and other fees & 0.26 & 0.26 \\
c) Cost of drug $(a+b)$ & 3.76 & 1.21 \\
d) Margins (about 14\%) & 0.51 & 0.16 \\
e) Selling price $(c+d)$ & 4.27 & 1.37 \\
ADF Project & & \\
f) Purchase price & 1.07 & 0.83 \\
g) Freight and other fees & 0.49 & 0.49 \\
h) Transit fee & 0.22 & 0.22 \\
i) Cost of drug (f $+g+h)$ & 1.78 & 1.54 \\
j) Margin (about 10\%) & 0.2 & 0.13 \\
k) Selling price $(i+j)$ & 1.98 & 1.68 \\
\hline
\end{tabular}

Note: CAL, comprehensive approach to lung health project; CAME, central pharmacy for essential medicines of Benin.

\section{Expenditure and recovery of the Revolving Drug Fund as} of January 2013

Between 2008 to 2013, the Benin NTP placed three orders for a total of 7,386 inhaled beclometasone and four orders for a total of 8,865 inhaled salbutamol with an expenditure of $24,887 €$ through the ADF. In addition, the Benin NTP spent $4,338 €$ procuring peak flow meters and mouthpieces through the ADF, and printing asthma posters, asthma treatment cards and registers. The total expenditure of the RDF was $29,225 €$ (Table 3).

Table 4 shows the number of inhalers to be sold and selling price per inhaler. Complete collection of money from the sale of these inhalers would generate $50,474 €$ for the RDF. Table 5 shows that a total of $32,211 €$ has been recovered so far from selling inhalers to patients. The value of the inhalers in stock was equivalent to $12,172 €$. The value of inhalers that were expired or provided to the poorest patients free-of-charge amounted to 6,091€.

Table 6 shows that the capital of the RDF as of 31 January 2013, including the deposit in the RDF bank account $(8,114 €)$ and the value of inhalers in stock $(12,172 €)$, was equivalent to $20,586 €$, which was less than $24,101 €$, the total amount of capital initially injected into the RDF. The decrease in the RDF was mainly because a number of inhalers were expired or provided free-of-charge $(6,091 €)$ and because part of the fund was used to procure other items required for the management of asthma patients $(4,338 €)$.

\section{Estimations for the next order}

Table 7 shows the use of the tool on 31 January 2013, which estimated that the date for placing the next order of inhalers would be in July 2013. Consequently, the NTP Benin sent an order to ADF in July 2013 to prevent interruption of supply.

The assessment found that there was no interruption of supply of asthma medicines from 2008-2013 in asthma pilot sites in Benin.

Table 3 Asthma revolving drug fund expenditure for medicines and other items related to asthma management, Benin 2008-2013

\begin{tabular}{|c|c|c|c|c|c|}
\hline Orders & $\begin{array}{l}\text { Number of inhalers } \\
\text { procured (1) }\end{array}$ & $\begin{array}{l}\text { Purchase price per } \\
\text { inhaler }(€)(2)\end{array}$ & $\begin{array}{l}\text { Purchase price, total } \\
\text { inhalers }(€)(3=1 * 2)\end{array}$ & $\begin{array}{l}\text { Transport and ADF } \\
\text { fees }(€)(4)\end{array}$ & $\begin{array}{l}\text { Total cost }(€) \\
(3+4)\end{array}$ \\
\hline \multicolumn{6}{|l|}{ Beclometasone } \\
\hline 1st order & 1,386 & 1.07 & 1,483 & 2,557 & 4,040 \\
\hline 2nd order & 3,000 & 0.99 & 2,970 & 1,135 & 4,111 \\
\hline $3 r d$ order & 3,000 & 0.99 & 2,970 & 2,747 & 5,717 \\
\hline (a) Subtotal & 7,386 & & 7,423 & 6,438 & 13,867 \\
\hline \multicolumn{6}{|l|}{ Salbutamol } \\
\hline 1st order & 681 & 0,83 & 565 & 329 & 894 \\
\hline 2nd order & 3,114 & 0.83 & 2,585 & & 2,585 \\
\hline $3 r d$ order & 2,520 & 0.84 & 2,117 & 1,178 & 3,287 \\
\hline 4th order & 2,550 & 0.83 & 2,117 & 2,149 & 4,254 \\
\hline (b) Subtotal & 8,865 & & 7,382 & 1,507 & 11,020 \\
\hline $\begin{array}{l}\text { (c) Expenditure for procuring } \\
\text { inhalers }(a+b)\end{array}$ & & & & & 24,887 \\
\hline (d) Other expenditure & & & & & 4,338 \\
\hline Total expenditure $(c+d)$ & & & & & 29,225 \\
\hline
\end{tabular}


Table 4 Number of inhalers to be sold, selling price per inhaler and money to be recovered for asthma revolving drug fund in Benin by 31 January 2013

\begin{tabular}{llll}
\hline Medicines & $\begin{array}{l}\text { Number } \\
\text { of inhalers }\end{array}$ & $\begin{array}{l}\text { Sellling price } \\
\text { per inhaler }(€)\end{array}$ & $\begin{array}{l}\text { Money to be } \\
\text { recovered by } \\
\text { selling inhalers }(€)\end{array}$
\end{tabular}

\begin{tabular}{llll}
\hline CAL project & & & \\
Beclometasone & 2,320 & 4.27 & 9,906 \\
Salbutamol & 2,000 & 1.37 & 2,740 \\
ADF project & & & \\
Beclometasone & $9,886^{*}$ & 1.98 & 19,574 \\
Salbutamol & $10,865 \dagger$ & 1.68 & 18,253 \\
Total & & & 50,474 \\
\hline
\end{tabular}

Note: CAL, comprehensive approach to lung health project; ADF, Asthma Drug Facility.

*Includes 2500 donated by the ADF and 7386 procured through the ADF. tIncludes 2000 donated by the ADF and 8865 procured through the ADF.

\section{Asthma patient management}

The results of asthma management during the CAL project have been reported [11]. Since the beginning of the ADF pilot project in April 2010, asthma management has been performed consistently and quarterly reports sent to The Union during the three years of the project. The number of patients with persistent asthma newly registered was 204 in the first project year (April 2010-March

Table 5 Funds recovered by the asthma revolving drug fund in Benin by 31 January 2013

\begin{tabular}{|c|c|c|c|}
\hline Medicines & $\begin{array}{l}\text { Number } \\
\text { of inhalers }\end{array}$ & $\begin{array}{l}\text { Selling price } \\
\text { per inhaler }(€)\end{array}$ & $\begin{array}{l}\text { Value of } \\
\text { inhalers }(€)\end{array}$ \\
\hline 1) Lost or provided free & & & 6,091 \\
\hline \multicolumn{4}{|l|}{ CAL project } \\
\hline Beclometasone & 879 & 4.27 & 3,753 \\
\hline Salbutamol & 250 & 1.37 & 343 \\
\hline \multicolumn{4}{|l|}{ ADF project } \\
\hline Beclometasone & 283 & 1.98 & 560 \\
\hline Salbutamol & 854 & 1.68 & 1,435 \\
\hline 2) Money already recovered & & & 32,211 \\
\hline \multicolumn{4}{|l|}{ CAL project } \\
\hline Beclometasone & 1,441 & 4.27 & 6,153 \\
\hline Salbutamol & 1,750 & 1.37 & 2,398 \\
\hline \multicolumn{4}{|l|}{ ADF project } \\
\hline Beclometasone & 6,213 & 1.98 & 12,302 \\
\hline Salbutamol & 6,761 & 1.68 & 11,358 \\
\hline 3) ADF inhalers in stock & & & 12,172 \\
\hline Beclometasone & 3,390 & 1.98 & 6,712 \\
\hline Salbutamol & 3,250 & 1.68 & 5,460 \\
\hline Total $(1+2+3)$ & & & 50,474 \\
\hline
\end{tabular}

Note: CAL, comprehensive approach to lung health project; ADF, Asthma Drug Facility.
Table 6 Capital of asthma revolving drug fund in Benin, as of January 2013

\begin{aligned} & \hline Total amount $(\boldsymbol{\epsilon}) \\ &$\hline 1. Balance in Bank $(a+b-c) 8,414 \\ &$ a) Grant in cash 5,428 \\ & b) Monies recovered from medicines $32,211^{*} \\ &$ c) Expenditure $29,225+ \\ &$ 2. Value of inhalers in stock $12,172 \ddagger \\ &$ Total $(1+2) 20,586 \\ &$\hline\end{aligned}

*See Table 5, money already recovered.

†See Table 3, total expenditure.

‡See Table 5, ADF inhalers in stock.

2011). It increased to 231 in the second year (April 2011March 2012) and to 274 in the third year (April 2012March 2013). In addition to the 709 newly registered cases with persistent asthma, patients with intermittent asthma and patients registered prior to the ADF pilot project were also treated with medicines provided through the ADF.

\section{Discussion}

Before the asthma pilot project, only a small minority of asthma patients were prescribed with ICS in Benin [12]. The CAL asthma pilot project began with national adaption of international asthma guidelines, followed by training of clinicians for guideline implementation. To ensure sustainability of the long-term management of asthma, an uninterrupted supply of ICS is essential, for which a RDF of asthma was established in Benin. The RDF provided ICS at affordable prices for the majority of asthma patients. For a small minority of poor asthma patients who could not afford to pay, the ICS were provided at no cost.

Since the beginning of the asthma project in 2008, long-term management of asthma using ICS has reduced suffering and improved the quality of life of asthma patients. The proportion of asthma patients who had at least one visit to emergency services in the previous year for an asthma attack was $59.4 \%$ before the project, which reduced to $1.6 \%$ after the project [12].

Since the establishment of the RDF, the capital of the fund was always sufficient to ensure uninterrupted supply of asthma medicines in the five pilot sites. Management of patients with persistent asthma using ICS has became routine practice in the pilot sites. The tool for managing medicine ordering was useful as it estimated the number of months covered by inhalers in stock and the approximate date when the next medicine order should be placed. The tool did not use the number of asthma patients to estimate consumption because the severity of asthma may vary over time and patients may not follow advice to continue treatment when their asthma is under control. If the RDF is maintained properly, it might 
Table 7 Estimation of the date for placing the next order of asthma inhalers, revolving drug fund, Benin, 31 January 2013

\begin{tabular}{|c|c|c|c|c|c|c|c|c|c|c|}
\hline Medicines & $\begin{array}{l}\text { Number of } \\
\text { inhaler in } \\
\text { stock (a) }\end{array}$ & $\begin{array}{l}\text { Date } \\
\text { begin } \\
\text { (b) }\end{array}$ & $\begin{array}{l}\text { Medicines } \\
\text { ordered during } \\
\text { the period (c) }\end{array}$ & $\begin{array}{l}\text { Date } \\
\text { end (d) }\end{array}$ & $\begin{array}{l}\text { Number of } \\
\text { inhalers } \\
\text { remaining } \\
\text { (e) }\end{array}$ & $\begin{array}{l}\text { Consumption } \\
\text { during the period } \\
(f=a+c-e)\end{array}$ & $\begin{array}{l}\text { Number of } \\
\text { months during } \\
\text { the period }(\mathrm{g})\end{array}$ & $\begin{array}{l}\text { Average } \\
\text { monthly } \\
\text { consumption } \\
(h=f / g)\end{array}$ & $\begin{array}{l}\text { Estimation of the number } \\
\text { of months covered by } \\
\text { inhalers in stock }(i=f / h)\end{array}$ & $\begin{array}{l}\text { Approximate date of placing } \\
\text { next medicine order (i-8*) } \\
\text { months since (d) }\end{array}$ \\
\hline Beclometasone & 1600 & $\begin{array}{l}15 / 09 / \\
2012\end{array}$ & 3000 & $\begin{array}{l}31 / 01 / \\
2013\end{array}$ & 3390 & 1210 & 4.6 & 263 & 12,9 & $26 / 06 / 2013$ \\
\hline Salbutamol & 2130 & $\begin{array}{l}15 / 09 / \\
2012\end{array}$ & 2250 & $\begin{array}{l}31 / 01 / \\
2013\end{array}$ & 3250 & 1130 & 4.6 & 246 & 13,2 & 06/07/2013 \\
\hline
\end{tabular}

*Ordering must be started as soon as the number of inhalers in stock is sufficient for only 8 months: 2 months for reserve stock and 6 months as turnaround time between ordering and arrival of inhalers. 
be possible to extend the management of asthma to other sites using medicines provided by the RDF.

Several challenges should be highlighted. First, the government's political commitment for national asthma control was not yet in place and funding for the management of non-communicable diseases was lacking. It is challenging to ensure sustainibility of the long-term management of asthma. Second, maintaining a private bank account for the RDF in a public health structure and keeping the health personnel motivated to manage the distribution of medicines and the replenishment of stock with monies collected from the sale of medicines over a prolonged period of time might be challenging. Several issues arose during project implementation, such as expiry of medicines, money from medicine sales not recovered, medicines provided for free but not recorded, and money from medicine sales recovered but not registered. Consequently, the capital of the RDF was not fully recovered, resulting in a decrease of capital after five years of operation.

The Pan American Health Organization (PAHO) has established the PAHO Strategic Fund to assist PAHO member states in the procurement of essential medicines and basic public health products [18]. In 2013, PAHO started to add medicines for Non-Communicable Diseases (NCD) to this fund. However, there is no such regional procurement mechanism in place in Africa. The World Health Organization (WHO) has been advocating for universal health coverage to ensure access to health care, for which countries must raise sufficient funds, reduce the reliance on direct payments to finance services, and improve efficiency and equity [19]. Furthermore, the WHO Global Action Plan for Prevention and Control of NCD 2013-2020 has set the target of " $80 \%$ availability of the affordable basic technologies and essential medicines" [20]. This target applies to asthma inhalers. Until universal health coverage is implemented and providing access to care for asthma patient in Benin, the RDF will continue playing an important role in ensuring an uninterrupted supply of essential asthma medicines.

\section{Conclusion}

The Benin experience demonstrated that in countries where universal health coverage was not yet in place, establishment of a RDF may help maintain an uninterrupted supply of essential medicines.

\footnotetext{
Abbreviations

ADF: Asthma Drug Facility; CAL: Comprehensive approach to lung health; CAME: Central pharmacy for essential medicines; CFC: Chlorofluorocarbons; CNHP: Centre national hospitalier de pneumophtisiologie; ICS: Inhaled corticosteroid; HFA: Hydrofluoroalkanes; NCD: Non-Communicable Diseases; NTP: National tuberculosis programme; PAHO: Pan American Health Organization; RDF: Revolving drug fund; The Union: International Union Against Tuberculosis and Lung Disease; WHO: World Health Organization.
}

\section{Competing interests}

The authors declare that they have no competing interests.

\section{Authors' contributions}

GA, NAK, MG, CP, KB, NB, DAE, CYC designed the study. GA, NAK, MG, LT, WB collected data. GA, NAK, MG, CP, KB, NB, DAE, CYC interpreted findings. GA, NAK, CYC wrote the first draft of the manuscript. All authors contributed to the revision of the manuscript and gave approval to the final version of the manuscript.

\section{Acknowledgements}

Authors wish to thank Cécile Macé who participated in the establishment of the revolving drug fund, Gabriel Ade and Ferdinand Kassa who managed asthma patients, and Angelo Makpenon who helped data collection. The study was funded by the International Union Against Tuberculosis and Lung Disease.

\section{Author details}

${ }^{1}$ Centre National Hospitalier de Pneumo phtisiolologie, Cotonou, Bénin. ${ }^{2}$ International Union Against Tuberculosis and Lung Disease, 68, boulevard Saint-Michel, 75006 Paris, France. ${ }^{3}$ Division of Pulmonary Medicine, Department of Internal Medicine, Wan Fang Hospital, Taipei Medical University, Taipei, Taiwan. ${ }^{4}$ Department of Internal Medicine, School of Medicine, College of Medicine, Taipei Medical University, Taipei, Taiwan.

Received: 20 November 2014 Accepted: 17 March 2015

Published online: 13 April 2015

\section{References}

1. Hogerzeil HV, Liberman J, Wirtz VJ, Kishore SP, Selvaraj S, Kiddell-Monroe R, et al. Promotion of access to essential medicines for non-communicable diseases: practical implications of the UN political declaration. Lancet. 2013;381:680-9.

2. Cameron A, Ewen M, Ross-Degnan D, Ball D, Laing R. Medicine prices, availability, and affordability in 36 developing and middle-income countries: a secondary analysis. Lancet. 2009;373:240-9.

3. Babar ZU, Lessing C, Mace C, Bissell K. The availability, pricing and affordability of three essential asthma medicines in 52 low- and middle-income countries. Pharmacoeconomics. 2013:31:1063-82.

4. Aït-Khaled N, Auregan G, Bencharif N, Mady Camara L, Dagli E, Djankine K, et al. Affordability of inhaled corticosteroids as a potential barrier to treatment of asthma in some developing countries. Int J Tuberc Lung Dis. 2000;4:268-71.

5. Aït-Khaled N, Enarson DA, Bissell K, Billo NE. Access to inhaled corticosteroids is key to improving quality of care for asthma in developing countries. Allergy. 2007:62:230-6.

6. Burney P, Potts J, Aitt-Khaled N, Sepulveda RMD, Zidouni N, Benali R, et al. A multinational study of treatment failures in asthma management. Int J Tuberc Lung Dis. 2008;12:13-8

7. The Global Asthma Report 2011. Paris, France: The International Union Against Tuberculosis and Lung Disease; 2011.

8. Murakami H, Phommasack B, Oula R, Sinxomphou S. Revolving drug funds at front-line health facilities in Vientiane, Lao PDR. Health Policy Plan. 2001;16:98-106.

9. Umenai T, Narula IS. Revolving drug funds in Asia and Latin America Lancet. 1996;347:1698-9.

10. Umenai T, Narula IS. Revolving drug funds: a step towards health security. Bull World Health Organ. 1999;77:167-71.

11. Ali GKM. How to establish a successful revolving drug fund: the experience of Khartoum state in the Sudan. Bull World Health Organ. 2009;87:139-42.

12. Ade G, Gninafon M, Tawo L, Aït-Khaled N, Enarson DA, Chiang C-Y. Management of asthma in Benin: the challenge of loss to follow-up. Public Health Action. 2013;3:76-80

13. Kan XH, Chiang C-Y, Enarson DA, Rao HL, Chen Q, Ait-Khaled N, et al. Asthma as a hidden disease in rural China: opportunities and challenges of standard case management. Public Health Action. 2012;2:87-91.

14. Billo NE. Asthma drug facility: from concept to reality. Int J Tuberc Lung Dis. 2006;10:709.

15. Billo NE. Good news: asthma medicines for all. Int J Tuberc Lung Dis 2010;14:524.

16. Ait-Khaled N, Enarson DA. Management of asthma in adults. A guide to essentials of good practice. Paris, France: International Union Against Tuberculosis and Lung Disease; 2005. 
17. Ait-Khaled N, Enarson DA, Chiang C-Y, Marks GB, Bissell K. Management of asthma: a guide to the essentials of good clinical practice. Paris, France: International Union Against Tuberculosis and Lung Disease; 2008.

18. Pan American Health Organization. About the PAHO Strategic Fund. [http:// www.paho.org/hq/index.php?option=com_content\&view=category\&layout= blog\&id=1159\&ltemid=452. Accessed 29 Mar 2014].

19. The World Health Report. Health system financing: the path to universal coverage. Geneva: World Health Organization; 2010.

20. World Health Organization. Global action plan for the prevention and control of noncommunicable diseases 2013-2020. Geneva: World Health Organization; 2013.

\section{Submit your next manuscript to BioMed Central} and take full advantage of:

- Convenient online submission

- Thorough peer review

- No space constraints or color figure charges

- Immediate publication on acceptance

- Inclusion in PubMed, CAS, Scopus and Google Scholar

- Research which is freely available for redistribution 